\title{
Resistência parcial à brusone de genótipos de trigo comum e sintético nos estádios de planta jovem e de planta adulta
}

\author{
Maria Fernanda A. Cruz¹, Ariano M. Prestes', João L. N. Maciel² \& Pedro L. Scheeren² \\ ${ }^{1}$ Faculdade de Agronomia e Medicina Veterinária, Universidade de Passo Fundo, 99001-970, Passo Fundo, RS, Brasil; \\ ${ }^{2}$ Embrapa Trigo, 99001-970, Passo Fundo, RS, Brasil
}

Autor para correspondência: Maria Fernanda A. Cruz, e-mail: fertunes@bol.com.br

\begin{abstract}
RESUMO
A brusone do trigo, causada pelo fungo Pyricularia grisea foi relatada pela primeira vez no Brasil, no estado do Paraná, em 1985. Desde então, busca-se, dentre o germoplasma disponível no País, cultivares resistentes à doença. O objetivo deste trabalho foi determinar o grau de resistência parcial de genótipos de trigo comum e de trigo sintético nos estádios de planta jovem e de planta adulta. Para a avaliação na fase de planta jovem foram escolhidos 70 genótipos de trigo, os quais foram submetidos à inoculação com 18 isolados de P. grisea. Dos 70 genótipos, 12 foram selecionados para a avaliação em planta adulta. Entre os genótipos resistentes em planta jovem destacaram-se BRS 229, BRS 179, CNT 8, BRS 120 e BRS Buriti. No estádio de planta adulta, os genótipos CNT 8, NE 20156-B, PF 844001, PF 964009 e PF 804002 foram aqueles que apresentaram menor severidade da doença.
\end{abstract}

Palavras-chave: Pyricularia grisea, Triticum aestivum, genes de resistência.

\begin{abstract}
Partial resistance to blast on common and synthetic wheat genotypes in seedling and in adult plant growth stages

Wheat blast caused by Pyricularia grisea was first reported in Brazil in 1985 in the state of Paraná. From then on, researchers have been looking for resistant genotypes to blast disease among Brazilian wheat germplasm. The objective of this work was to determine the level of partial resistance of synthetic and common wheat genotypes in young and adult plant growth stages. In young plant tests 70 wheat genotypes were challenged by 18 isolates of $P$. grisea. Twelve of the 70 genotypes were selected for adult plant tests. Among all genotypes evaluated BRS 229, BRS 179, CNT 8, BRS 120, and BRS Buriti showed better resistance level when tested at young plant growths stages. However, CNT 8, NE 20156-B, PF 844001, PF 964009 and PF 804002 showed less leaf and head area affected by blast in adult plant.
\end{abstract}

Keywords: Pyricularia grisea, Triticum aestivum, resistance genes.

\section{INTRODUÇÃO}

A brusone do trigo, causada pelo fungo Pyricularia grisea Sacc. (teleomorfo: Magnaporthe grisea (T.T. Hebert) M.E. Barr), foi diagnosticada no Brasil em 1985, no estado do Paraná (Igarashi et al. 1986). Desde então, a busca por resistência em cultivares de trigo das principais regiões tritícolas do Brasil tem sido intensa (Goulart et al., 1995; Goulart 2004). Entretanto, a resistência de um determinado cultivar, numa região geográfica, nem sempre se confirma em outras regiões ou mesmo em condições controladas de inoculação. Segundo Urashima et al. (2004), as diferenças entre resultados obtidos em diferentes experimentos podem ser atribuídas à variabilidade do patógeno. Os fungos filamentosos assim como $P$. grisea apresentam mecanismos de variabilidade genética que lhes conferem uma maior adaptação a ambientes e hospedeiros distintos. A variabilidade patogênica do gênero Pyricularia foi demonstrada, entre outras formas, pela diferenciação de raças originárias de uma mesma lesão em arroz (Ou \& Ayad, 1968), ou ainda pelas mudanças de raças patogênicas em um viveiro de brusone durante o período de um mês (Quamaruzzaman \& Ou, 1970). Embora, não existam informações sobre a existência de raças patogênicas de $P$. grisea do trigo acredita-se que a variabilidade genética do patógeno seja de extrema importância para a agressividade do fungo. Assim, torna-se necessário submeter cultivares de trigo a inoculações com isolados representativos de diferentes populações do patógeno, para que seja possível a identificação de genótipos resistentes, uma vez que as informações disponíveis na literatura sobre possíveis fontes de resistência à brusone ainda são insuficientes.

A busca por fontes de resistência à brusone tem sido apontada como prioritária em programas de melhoramento de trigo destinados a gerar cultivares para o cultivo em locais com histórico de ocorrência da doença no Brasil. Devido à baixa variabilidade genética dentro do gênero Triticum aestivum, algumas espécies geneticamente afins ao trigo cultivado aparecem como alternativa para exploração de genes de resistência à brusone. Germoplasma dessas espécies como, Triticum tauschii (sinonímia Aegilops squarrosa, Aegilops tauschii) já foi explorado como fonte 
de resistência a manchas foliares (Prestes et al., 1994) com resultados satisfatórios. Acessos dessa espécie também apresentaram reação de resistência a isolados de $P$. grisea, em ensaios conduzidos por Urashima \& Kato (1994), demonstrando a importância da utilização dessa espécie em programas de melhoramento que visem resistência a doenças de trigo.

No patossistema trigo - $P$. grisea ainda não são conhecidos quaisquer genes de resistência vertical à brusone, além do que, no Brasil, tem sido identificados apenas genótipos com resistência parcial à doença (Trindade et al., 2006). Dessa forma, a avaliação criteriosa do nível de resistência parcial à brusone que os genótipos de trigo do Brasil apresentam é uma condição indispensável para se avançar em qualquer programa de melhoramento de trigo que tenha como um dos seus objetivos a geração de cultivares menos suscetíveis à doença. A resistência incompleta ou parcial é definida como um tipo de resistência quantitativa, raça não-específica, na qual, embora o hospedeiro apresente reação de suscetibilidade, verifica-se baixa severidade da doença (Parlevliet, 1979; 1985). Na maioria dos patossistemas a resistência é de origem poligênica, embora em alguns casos tenha sido relatada resistência parcial de herança oligo ou monogênica (Parlevliet, 1985).

Além da falta de informações sobre genótipos resistentes à brusone, desconhece-se também o estádio de desenvolvimento da planta em que a resistência se expressa. Nesse sentido, resultados obtidos para a cultura do arroz ao longo dos vários anos de pesquisa mostram que a relação entre reação de resistência à brusone em planta jovem e em planta adulta é discrepante. De acordo com Prabhu \& Filippi (2006) a expressão da resistência nas panículas é menos completa e mais complexa que em folhas. Nas folhas e nas panículas a resistência é controlada por diferentes genes herdados independentemente. Entretanto, Arruda et al. (2005) evidenciaram correlação positiva entre suscetibilidade de folhas no estádio vegetativo e de espigas. O objetivo deste trabalho foi verificar o grau de resistência parcial de genótipos de trigo comum e sintético à brusone nos estádios de planta jovem e planta adulta.

\section{MATERIAL E MÉTODOS}

A pesquisa foi conduzida no Laboratório de Fitopatologia e em casa-de-vegetação da Embrapa Trigo, em Passo Fundo, Rio Grande do Sul. Foram utilizados 18 isolados monospóricos de P. grisea, (Tabela 1) obtidos de amostras de plantas de trigo com brusone, provenientes dos estados do Rio Grande do Sul, Paraná, Minas Gerais e Goiás. Os isolados foram obtidos de folhas, ráquis e de glumas de trigo com sintomas de brusone. Efetuou-se assepsia do material, que permaneceu em câmara úmida por 24 horas. Em seguida, com o auxílio de uma lupa procedeuse o isolamento através da transferência dos conídios para o meio ágar-água e, após 15 horas, apenas os conídios germinados foram transferidos para o meio aveia-ágar para o desenvolvimento da colônia. Após os isolados foram preservados pelo método do papel filtro (Prabhu \& Filippi, 2006).

\section{Genótipos}

Na primeira etapa do trabalho foram avaliados 70 genótipos de trigo sendo, cinqüenta cultivares comerciais ou linhagens de trigo hexaplóide e os demais genótipos

TABELA 1 - Isolados monospóricos de P. grisea do trigo (Py) utilizados nas inoculações nos estádios de planta jovem e de planta adulta

\begin{tabular}{|c|c|c|c|c|c|}
\hline $\mathrm{N}^{\mathrm{o}}$ & Designação & Origem & Cultivar & Segmento da planta & Ano \\
\hline 1 & Py 5001 & São Borja-RS & BRS Angico & Ráquis & 2005 \\
\hline 2 & Py 5002 & São Borja-RS & BRS Angico & Ráquis & 2005 \\
\hline 3 & Py 5005 & Londrina-PR & BRS 248 & Ráquis & 2005 \\
\hline 4 & Py 5012 & Londrina-PR & BRS 229 & Ráquis & 2005 \\
\hline 5 & Py 5017 & Londrina-PR & BRS 193 & Ráquis & 2005 \\
\hline 6 & Py 5020 & Londrina-PR & BR 18 & Ráquis & 2005 \\
\hline 7 & Рy 5021 & Londrina-PR & BR 18 & Ráquis & 2005 \\
\hline 8 & Py 5025 & Londrina-PR & BRS 249 & Ráquis & 2005 \\
\hline 9 & Py 5029 & Londrina-PR & CD 105 & Ráquis & 2005 \\
\hline 10 & Py 5038 & Londrina-PR & BRS 220 & Ráquis & 2005 \\
\hline 11 & Рy 5039 & Londrina-PR & BRS 208 & Ráquis & 2005 \\
\hline 12 & Py 6001 & Coromandel-MG & BRS 208 & Folha & 2006 \\
\hline 13 & Рy 6008 & Coromandel-MG & BRS 208 & Folha & 2006 \\
\hline 14 & Py 6010 & Coromandel-MG & BRS 208 & Folha & 2006 \\
\hline 15 & Py 6012 & Coromandel-MG & BRS 208 & Gluma & 2006 \\
\hline 16 & Рy 6018 & Coromandel-MG & BRS 208 & Ráquis & 2006 \\
\hline 17 & Py 6025 & Coromandel-MG & BRS 208 & Folha & 2006 \\
\hline 18 & Py 6030 & Goiânia-GO & BRS 208 & Ráquis & 2006 \\
\hline
\end{tabular}


de trigo hexaplóide sintético, resultante do cruzamento entre Triticum durum e Aegilops squarrosa (Triticum tauschii). Os genótipos utilizados fazem parte do Banco de Germoplasma (BAG) da Embrapa Trigo, os mesmos foram inoculados no estádio de planta jovem (estádio 14 da escala de Zadoks et al., 1974). Os genótipos foram escolhidos através de uma seleção em que se procurou estabelecer um grupo com ampla diversidade genética (Tabela 2). Para a avaliação da reação em planta adulta (estádio 61 da escala de Zadoks et al., 1974), foram selecionados 12 genótipos dentre os 70 avaliados no estádio de planta jovem, sendo eles, cinco genótipos de trigo sintético (NE 20156-B; PF 844001; PF 844002; PF 964009; PF 804002) e, os outros sete, cultivares de trigo pra panificação (CNT8; BRS 120; BRS 194; BRS Buriti; BR 18; BRS Camboatá e BRS Louro). Para a avaliação em planta adulta os genótipos foram semeados em vasos com capacidade de $3 \mathrm{~kg}$ de solo, em quatro repetições com quatro plantas. Para os testes em planta jovem, os genótipos foram semeados em copos de plásticos com capacidade de $0,5 \mathrm{~kg}$, preenchidos com solo de lavoura, em três repetições, cada uma com oito plantas. Em ambas as avaliações, o delineamento experimental utilizado foi de blocos ao acaso.

\section{Preparação do inóculo e inoculações}

Os isolados preservados em papel-filtro foram repicados para placas de Petri com meio de aveia-ágar e incubados em câmara de crescimento à temperatura de $23 \mathrm{a}$ $25^{\circ} \mathrm{C}$, por 12 dias. Para obtenção da suspensão do inóculo, os conídios foram removidos da placa com o auxílio de um pincel e água destilada acrescida com espalhante adesivo Tween 80 . O volume de suspensão para cada inoculação em planta jovem foi de $500 \mathrm{~mL}$ e para planta adulta, $300 \mathrm{~mL}$, numa concentração de $2 \times 10^{5}$ conídios $/ \mathrm{mL}$.

Previamente à inoculação, as plantas foram climatizadas por 24 horas, àtemperatura de $24^{\circ} \mathrm{C}$ e fotoperíodo 12 horas. A inoculação nas folhas das plantas jovens foi

TABELA 2 - Genótipos de trigo avaliados nas inoculações com os 18 isolados monospóricos de P. grisea do trigo

\begin{tabular}{|c|c|c|c|c|c|}
\hline $\mathrm{N}^{\circ}$ & Origem & Genótipos & $\mathrm{N}^{\circ}$ & Origem & Genótipos \\
\hline $1 *$ & 2 & NE 20156-B & 36 & 65 & EMBRAPA 40 \\
\hline 2 & 5 & NE 20157-X & 37 & 66 & FRONTANA \\
\hline 3 & 6 & NE 20160-C & 38 & 67 & IAC 5 \\
\hline 4 & 8 & PF 844001 & 39 & 68 & IAC 24 \\
\hline 5 & 9 & PF 844002 & 40 & 69 & IAPAR 6 \\
\hline 6 & 23 & PF 964009 & 41 & 71 & IAS 54 \\
\hline 7 & 25 & PF 804001 & 42 & 72 & JACUÍ \\
\hline 8 & 26 & PF 804002 & 43 & 73 & KLEIN \\
\hline 9 & 31 & NE $20158-X$ & 44 & 74 & LA 1549 \\
\hline 10 & 32 & NE 20159-B & 45 & 75 & OCEPAR 16 \\
\hline 11 & 33 & NE 20159-C & 46 & 76 & PELADINHO \\
\hline 12 & 34 & NE 20159-X & 47 & 77 & PG 1 \\
\hline 13 & 36 & NE $20159-Z$ & 48 & 79 & TOROPI \\
\hline 14 & 37 & NE $20160-A$ & 49 & 80 & OR 1 \\
\hline 15 & 38 & NE 20160-B & 50 & 81 & NOBRE \\
\hline 16 & 39 & NE 20160-Y & 51 & 82 & ALIANÇA \\
\hline 17 & 40 & NE 20160-Z & 52 & 83 & BRS 120 \\
\hline 18 & 43 & IPF 71404 & 53 & 84 & BRS 177 \\
\hline 19 & 102 & SINTÉTICO 01 & 54 & 85 & BRS 179 \\
\hline 20 & 47 & NE 20168-P & 55 & 86 & BRS 194 \\
\hline 21 & 50 & ANAHUAC & 56 & 87 & BRS 208 \\
\hline 22 & 51 & BH 1146 & 57 & 88 & BRS 209 \\
\hline 23 & 52 & BR 12 & 58 & 89 & BRS 210 \\
\hline 24 & 53 & BR 14 & 59 & 90 & BRS 220 \\
\hline 25 & 54 & BR 18 & 60 & 91 & BRS 229 \\
\hline 26 & 55 & BR 23 & 61 & 92 & BURITI \\
\hline 27 & 56 & BR 33 & 62 & 93 & CAMBOATÁ \\
\hline 28 & 57 & BR 35 & 63 & 94 & GUABIJU \\
\hline 29 & 58 & CEP 14 & 64 & 95 & LOURO \\
\hline 30 & 59 & CEP 19 & 65 & 96 & TIMBAÚVA \\
\hline 31 & 60 & CEP 24 & 66 & 97 & BRILHANTE \\
\hline 32 & 61 & CNT 8 & 67 & 98 & IAPAR 53 \\
\hline 33 & 62 & CNT 10 & 68 & 99 & IPR 85 \\
\hline 34 & 63 & EMBRAPA 16 & 69 & 100 & PF 001102 \\
\hline 35 & 64 & EMBRAPA 27 & 70 & 101 & BRS 49 \\
\hline
\end{tabular}

*genótipos numerados de 1 a 20 são de trigo sintético, os demais são genótipos de trigo comum hexaplóide. 
realizada no estádio em que as plantas apresentavam quatro folhas expandidas e, em plantas adultas, no início da antese, correspondendo, respectivamente, aos estádios 14 e 61 da escala de Zadoks et al. (1974). Para a inoculação utilizou-se um atomizador "De Vilbiss", acoplado a um compressor de ar para. Após a inoculação as plantas foram mantidas por 24 horas em escuro total, na temperatura de $24^{\circ} \mathrm{C}$ sob nebulização de 120 segundos, em intervalos de 60 segundos. Decorridas as 24 horas, o fotoperíodo foi ajustado para 12 horas de luz e a nebulização para 60 segundos a cada 1800 segundos.

\section{Avaliações}

No presente trabalho avaliou-se a severidade das lesões do tipo 3 e 4 (Urashima et al., 2004) em folhas de plantas jovens e adultas de trigo. Em planta jovem, para cada uma das oito plantas de cada vaso, foi avaliada a folha $\mathrm{A}_{2}$ (Haun, 1973), totalizando 24 folhas avaliadas por genótipo. No estádio de planta adulta, de cada um dos quatro vasos, correspondendo a cada uma das quatro repetições do experimento, a severidade da doença foi avaliada em quatro folhas-bandeira e em quatro espigas.

A severidade da doença nas folhas, nos dois estádios foi transformada com o auxílio da escala diagramática preconizada pelo International Rice Research Institute (IRRI, 1996), com modificações, para as doenças do arroz onde: zero é ausência de sintomas; 1 (um), 0,1 a 4 \% da área foliar infectada (AFI); 2 (dois), 5 a 10\% AFI; 3 (três), 11 a $25 \% \mathrm{AFI} ; 4$ (quatro), 26 a 50\% AFI; 5 (cinco), 51 a 100\% da AFI. Na avaliação da infecção nas espigas, empregou-se a mesma escala descrita, mas considerando-se simplesmente $a$ área da espiga afetada pela doença.

\section{Análise estatística}

Para agrupar os 70 genótipos de acordo com a severidade das lesões de suscetibilidade observado no estádio de planta jovem, foram utilizadas as médias da severidade da doença que cada genótipo apresentou quando inoculado com cada um dos 18 isolados. Para o agrupamento dos dados utilizou-se o método UPGMA e o programa computacional Darwin (Perrier \& Jacquemoud-Collet, 2006). Para a estimativa de dissimilaridade de severidade utilizou-se a distância euclidiana. A distância euclidiana é considerada como uma medida de dissimilaridade, interpretada como sendo a distância entre dois indivíduos cujas posições são determinadas em relação às suas coordenadas definidas com referência a um grupo de eixos cartesianos, os quais possuem ângulos retos entre si, dados pela fórmula:

$\mathrm{d}_{\mathrm{ij}}=\left[\left(\mathrm{x}_{\mathrm{ia}}-\mathrm{x}_{\mathrm{ja}}\right)^{2}+\left(\mathrm{x}_{\mathrm{ib}}-\mathrm{x}_{\mathrm{jb}}\right)^{2}\right]^{1 / 2}$ na qual:

$\mathrm{x}_{\mathrm{ia}} \mathrm{e}_{\mathrm{ib}}=$ as características a e $\mathrm{b}$ do indivíduo $\mathrm{i}$;

$\mathrm{x}_{\mathrm{ja}}$ e $\mathrm{x}_{\mathrm{jb}}=$ as características a e b do indivíduo $\mathrm{j}$.

O programa SAS (Statistical Analysis System, 2003) foi utilizado para análise dos dados de severidade em folha bandeira e espiga. Procedeu-se a análise da variância e as médias dos isolados e genótipos foram comparadas pelo teste Tukey a $5 \%$ de probabilidade.

\section{RESULTADOS E DISCUSSÃO}

Os dados de severidade em planta jovem permitiram separar os genótipos em três grupos utilizando-se os valores da distância euclidiana $(\mathrm{d}=3,00)$ (Tabela 3$)$. O grupo "a" com 52 genótipos apresentou a maior média de severidade (\%): 31,45, com amplitude de 16,07 a 61,65, desvio padrão 10,30. Esse grupo foi integrado por alguns genótipos com os mais altos índices $(>50 \%)$ de severidade como BRS Aliança, IAPAR 6 e LA 1549. No grupo "b" com 13 genótipos com média de $14,94(9,15$ a 24,02$)$ e desvio padrão 5,05, encontram-se os genótipos com as menores médias de severidade como: BRS 229, BRS 179, NE 20158X, CNT 8, BRS 120 e BRS Buriti. O grupo "c" com penas 5 indivíduos apresentou média de severidade de 27,53, amplitude de 18, 92 a 36,25, e desvio padrão de 7,83.

Pela análise dos dados de severidade em espiga o isolado mais virulento foi Py 5005, porém sem diferir dos isolados Py 6001, Py 6008, Py 6030 (Tabela 4). Quanto aos genótipos, CNT 8 apresentou menor área afetada, porém não diferiu do genótipo de trigo sintético PF 844001. Para folha bandeira os isolados mais virulentos foram Py 6001, Py 5002, Py 6030 e Py 5039, enquanto que as menores médias de severidade foram observadas nos genótipos de trigo sintético: NE 20156-B, PF 844001, PF 964009, PF 804002, que não diferiram do cultivar CNT 8 (Tabela 5). Na comparação entre inoculações no estádio vegetativo, o destaque foi para o isolado Py 5002, o qual foi o menos agressivo, já em planta adulta o isolado comportou-se como um dos mais agressivos nos genótipos testados.

A variação de $9,15 \%$ a $61,55 \%$ na severidade da doença na folha no estádio de planta jovem (Tabela 3) pode ser considerada um forte indicativo da importância que a resistência parcial representa para a brusone do trigo, considerando o germoplasma de trigo avaliado no experimento. Pois, o controle genético da resistência parcial pode envolver muitos genes de pequeno efeito e caracterização por diferentes níveis de severidade, como apresentado no trabalho, já a resistência vertical caracteriza-se por uma reação de hipersensibilidade não verificada nos genótipos testados. Dessa forma, o uso de alguns desses genótipos nos programas de melhoramento de trigo à brusone pode se tornar uma estratégia efetiva na busca de combinações genéticas que visem o controle da doença através da construção de cultivares resistentes. Embora a busca por resistência qualitativa à brusone tenha sido um dos principais objetivos da maioria dos programas de melhoramento de arroz ao longo dos anos, essa não garantiu a durabilidade da resistência, devido à capacidade do patógeno em superar a resistência de cultivares num período de dois a três anos de seu lançamento. A maioria dos genótipos não confirmou em planta adulta a resistência verificada em planta jovem para os mesmos isolados, com exceção do CNT 8, que se mostrou como o menos suscetível em todas as avaliações (planta jovem, folha bandeira e espiga). Resultado semelhante foi relatado por Arruda et al. (2005) com o cultivar BH 1146. 
M.F.A. Cruz et al.

TABELA 3 - Agrupamento dos 70 genótipos de planta jovem inoculados com 18 isolados de $P$. grisea de acordo com a similaridade dos dados de severidade

\begin{tabular}{|c|c|c|c|}
\hline $\begin{array}{l}\text { Grupo de } \\
\text { severidade }\end{array}$ & Genótipos & $X 1^{1}$ & $X 2^{2}$ \\
\hline \multirow{52}{*}{$\mathrm{a}$} & CNT 10 & 28,77 & 2,90 \\
\hline & CEP 24 & 22,27 & 2,70 \\
\hline & BRS 220 & 29,68 & 2,79 \\
\hline & BRS 210 & 26,07 & 2,70 \\
\hline & IAS 54 & 24,38 & 2,39 \\
\hline & Frontana & 21,85 & 2,50 \\
\hline & CEP 14 & 16,38 & 2,30 \\
\hline & IAC 5 & 29,50 & 2,80 \\
\hline & Embrapa 16 & 26,81 & 2,70 \\
\hline & BR 35 & 21,12 & 2,34 \\
\hline & Brilhante & 22,02 & 2,43 \\
\hline & PF 804002 & 16,07 & 2,20 \\
\hline & PF 964009 & 17,27 & 2,20 \\
\hline & PF 804001 & 21,34 & 2,30 \\
\hline & BR 23 & 18,74 & 2,02 \\
\hline & IAC 24 & 28,99 & 2,50 \\
\hline & Jacuí & 24,43 & 2,50 \\
\hline & NE 20159-X & 28,66 & 2,61 \\
\hline & PF 844002 & 18,21 & 2,03 \\
\hline & NE 20168-P & 28,52 & 2,62 \\
\hline & IPF 71404 & 25,45 & 2,47 \\
\hline & BR 18 & 22,99 & 2,54 \\
\hline & Ocepar 16 & 35,69 & 2,94 \\
\hline & Embrapa 40 & 31,43 & 2,80 \\
\hline & NE 20156-B & 18,51 & 2,18 \\
\hline & BR 14 & 38,85 & 3,20 \\
\hline & BR 12 & 45,99 & 3,30 \\
\hline & BH 1146 & 33,48 & 2,82 \\
\hline & Sintético 01 & 31,29 & 2,87 \\
\hline & Toropi & 28,76 & 2,91 \\
\hline & NE 20160-Z & 36,90 & 3,06 \\
\hline & NE 20160-C & 44,12 & 3,20 \\
\hline & NE 20159-B & 34,32 & 2,79 \\
\hline & PG 1 & 20,84 & 2,53 \\
\hline & Peladinho & 38,85 & 3,24 \\
\hline & NE 20160-Y & 31,66 & 2,91 \\
\hline & NE 20159-C & 25,61 & 2,71 \\
\hline & NE 20160-B & 42,16 & 3,18 \\
\hline & NE 20160-A & 38,08 & 3,01 \\
\hline & NE 20159-Z & 27,74 & 2,57 \\
\hline & BRS Camboatá & 32,39 & 2,76 \\
\hline & BRS Guabijú & 30,33 & 2,83 \\
\hline & PF 001102 & 47,97 & 3,54 \\
\hline & IPR 85 & 30,97 & 2,99 \\
\hline & BRS Nobre & 40,98 & 3,22 \\
\hline & IAPAR 6 & 53,99 & 3,50 \\
\hline & LA 1549 & 50,64 & 3,34 \\
\hline & Klein & 31,59 & 2,83 \\
\hline & BRS Aliança & 61,55 & 4,01 \\
\hline & BR 33 & 45,61 & 3,50 \\
\hline & Anahuac & 44,96 & 3,60 \\
\hline & BRS 208 & 40,86 & 3,10 \\
\hline \multirow{13}{*}{$\mathrm{b}$} & IAPAR 53 & 13,03 & 1,91 \\
\hline & CNT 8 & 10,64 & 1,76 \\
\hline & PF 844002 & 18,88 & 2,20 \\
\hline & PF 844001 & 20,97 & 2,20 \\
\hline & NE 20157-X & 21,41 & 2,25 \\
\hline & BRS 179 & 10,48 & 2,20 \\
\hline & NE 20158-X & 10,49 & 1,73 \\
\hline & BRS 229 & 9,15 & 1,50 \\
\hline & BRS Buriti & 11,91 & 1,56 \\
\hline & BRS 177 & 24,02 & 2,30 \\
\hline & Embrapa 27 & 13,44 & 1,90 \\
\hline & BRS 120 & 11,47 & 1,73 \\
\hline & BRS 194 & 18,36 & 2,39 \\
\hline \multirow{5}{*}{$\mathrm{c}$} & BRS Timbaúva & 24,87 & 2,49 \\
\hline & BRS Louro & 18,92 & 2,20 \\
\hline & BRS 49 & 22,30 & 2,34 \\
\hline & BRS 209 & 35,33 & 2,90 \\
\hline & OR 1 & 36,25 & 3,00 \\
\hline
\end{tabular}

${ }^{1}$ Severidade média da brusone na folha.

${ }^{2}$ Severidade média da brusone na folha (X1), convertida em valores da escala do IRRI utilizada no experimento (X2). 
Resistência parcial à brusone de genótipos de trigo comum e sintético nos estádios...

TABELA 4 - Severidade de brusone em espiga de 12 genótipos de trigo, inoculados com 18 isolados monospóricos de $P$. grisea

\begin{tabular}{|c|c|c|c|c|c|c|c|c|c|c|c|c|c|}
\hline \multirow[b]{2}{*}{ Isolados } & \multicolumn{12}{|c|}{ Genótipos* } & \multirow[b]{2}{*}{ Média } \\
\hline & 2 & 8 & 9 & 23 & 26 & 54 & 61 & 83 & 86 & 92 & 93 & 95 & \\
\hline Рy 5001 & $2,0^{1}$ & 2,0 & 5,0 & 2,9 & 4,3 & 2,6 & 2,1 & 2,9 & 2,8 & 1,1 & 4,7 & 2,7 & $2,9 \mathrm{f}^{2}$ \\
\hline Рy 5002 & 2,3 & 4,2 & 5,0 & 5,0 & 3,9 & 4,8 & 0,3 & 4,3 & 3,7 & 4,2 & 5,0 & 4,6 & $3,9 b c$ \\
\hline Py 5005 & 4,8 & 4,8 & 5,0 & 5,0 & 4,5 & 5,0 & 3,1 & 5,0 & 4,4 & 4,3 & 5,0 & 5,0 & $4,6 \mathrm{a}$ \\
\hline Py 5012 & 4,1 & 2,5 & 4,5 & 3,2 & 1,3 & 2,6 & 1,9 & 1,1 & 2,1 & 3,5 & 4,9 & 5,0 & $3,0 \mathrm{ef}$ \\
\hline Py 5017 & 2,3 & 1,3 & 3,5 & 3,3 & 3,5 & 4,0 & 3,6 & 3,0 & 0,3 & 4,7 & 4,6 & 3,9 & $3,1 \mathrm{def}$ \\
\hline Рy 5020 & 4,5 & 2,8 & 4,9 & 3,3 & 3,2 & 3,4 & 2,0 & 1,7 & 4,2 & 4,1 & 3,6 & 4,6 & $3,5 \mathrm{cde}$ \\
\hline Рy 5021 & 3,0 & 2,1 & 5,0 & 2,1 & 2,0 & 3,8 & 3,5 & 5,0 & 3,2 & 4,8 & 2,9 & 4,8 & $3,5 \mathrm{cde}$ \\
\hline Py 5025 & 3,4 & 2,6 & 5,0 & 3,6 & 3,5 & 5,0 & 2,2 & 4,1 & 4,2 & 2,6 & 4,6 & 3,6 & $3,8 \mathrm{bc}$ \\
\hline Рy 5029 & 3,3 & 3,0 & 4,6 & 3,0 & 1,6 & 4,0 & 3,3 & 4,5 & 3,5 & 4,0 & 4,7 & 3,8 & $3,6 \mathrm{~cd}$ \\
\hline Рy 5038 & 0,8 & 0,1 & 4,7 & 0,0 & 0,1 & 1,0 & 0,1 & 0,0 & 1,2 & 2,1 & 0,7 & 1,0 & $1,0 \mathrm{~h}$ \\
\hline Рy 5039 & 2,3 & 2,7 & 2,4 & 1,4 & 2,1 & 5,0 & 3,0 & 4,8 & 2,0 & 5,0 & 5,0 & 5,0 & $3,4 \mathrm{cdef}$ \\
\hline Рy 6001 & 4,7 & 4,5 & 5,0 & 3,4 & 4,0 & 4,0 & 2,7 & 4,6 & 5,0 & 3,8 & 5,0 & 4,8 & $4,3 \mathrm{ab}$ \\
\hline Рy 6008 & 4,4 & 4,0 & 4,6 & 4,5 & 3,8 & 4,6 & 3,3 & 4,8 & 4,6 & 3,8 & 4,3 & 4,5 & $4,3 \mathrm{ab}$ \\
\hline Py 6010 & 0,5 & 1,6 & 4,7 & 0,2 & 0,1 & 1,3 & 0,8 & 3,8 & 0,2 & 4,3 & 3,6 & 4,2 & $2,1 \mathrm{~g}$ \\
\hline Рy 6012 & 0,1 & 0,6 & 1,8 & 1,2 & 1,5 & 0,6 & 0,3 & 2,0 & 0,8 & 1,5 & 0,6 & 1,0 & $1,0 \mathrm{~h}$ \\
\hline Рy 6018 & 0,0 & 1,0 & 0,9 & 0,0 & 2,1 & 0,5 & 1,3 & 3,2 & 1,5 & 2,5 & 1,7 & 2,4 & $1,4 \mathrm{~h}$ \\
\hline Рy 6025 & 1,3 & 0,3 & 4,8 & 0,0 & 0,7 & 0,5 & 0,9 & 2,5 & 0,9 & 1,4 & 2,7 & 0,5 & $1,3 \mathrm{~h}$ \\
\hline Рy 6030 & 4,8 & 3,0 & 4,6 & 3,1 & 4,5 & 5,0 & 1,8 & 4,8 & 4,4 & 4,9 & 5,0 & 4,7 & $4,2 \mathrm{ab}$ \\
\hline Média & $2,7 \mathrm{D}^{2}$ & $2,4 \mathrm{DE}$ & $4,2 \mathrm{~A}$ & $2,5 \mathrm{D}$ & $2,6 \mathrm{D}$ & $3,2 \mathrm{C}$ & $2,0 \mathrm{E}$ & $3,4 \mathrm{BC}$ & $2,7 \mathrm{D}$ & $3,5 \mathrm{BC}$ & $3,8 \mathrm{AB}$ & $3,7 \mathrm{~B}$ & \\
\hline
\end{tabular}

*Os números 2, 8, 9, 23, 26, 54, 61, 83, 86, 92, 93, 95.correspondem aos genótipos NE 20156-B,PF 844001, PF 844002, PF 964009, PF 804002, BR 18, CNT 8, BRS 120, BRS 194, BRS BURITI, BRS CAMBOATÁ, BRS LOURO, respectivamente.

${ }^{1}$ Valores correspondentes a s notas da escala utilizadas para classificar a severidade da doença nos diferentes genótipos de trigo

${ }^{2}$ Valores seguidos da mesma letra maiúscula na linha e minúscula na coluna não diferiram estatisticamente pelo testes de Tukey a $5 \%$

TABELA 5 - Severidade de brusone em folha bandeira de 12 genótipos de trigo inoculados com 18 isolados monospóricos de $P$. grisea

\begin{tabular}{|c|c|c|c|c|c|c|c|c|c|c|c|c|c|}
\hline \multirow[b]{2}{*}{ Isolados } & \multicolumn{12}{|c|}{ Genótipos* } & \multirow[b]{2}{*}{ Média } \\
\hline & 2 & 8 & 9 & 23 & 26 & 54 & 61 & 83 & 86 & 92 & 93 & 95 & \\
\hline Py 5001 & $3,2^{1}$ & 1,7 & 2,2 & 2,7 & 4,8 & 2,0 & 1,8 & 4,4 & 5,0 & 4,6 & 1,0 & 3,5 & $3,0 b^{2}$ \\
\hline Рy 5002 & 3,0 & 4,0 & 5,0 & 5,0 & 4,1 & 5,0 & 2,8 & 3,7 & 4,0 & 4,8 & 5,0 & 5,0 & $4,3 \mathrm{a}$ \\
\hline Рy 5005 & 2,2 & 2,8 & 3,8 & 2,5 & 2,1 & 2,5 & 1,8 & 5,0 & 0,7 & 2,3 & 3,5 & 3,3 & $2,7 \mathrm{~b}$ \\
\hline Рy 5012 & 3,6 & 0,1 & 0,4 & 3,5 & 1,4 & 0,1 & 2,9 & 0,7 & 4,0 & 0,2 & 2,7 & 2,9 & $1,8 \mathrm{c}$ \\
\hline Рy 5017 & 0,4 & 0,0 & 1,5 & 1,1 & 1,7 & 0,1 & 2,6 & 1,5 & 1,8 & 2,3 & 2,3 & 0,0 & 1,2 cde \\
\hline Py 5020 & 1,0 & 0,4 & 1,3 & 1,7 & 1,1 & 0,4 & 0,2 & 0,1 & 4,2 & 0,3 & 1,2 & 2,1 & $1,1 \mathrm{de}$ \\
\hline Рy 5021 & 0,6 & 2,8 & 4,6 & 1,5 & 1,5 & 4,4 & 3,9 & 4,1 & 0,4 & 4,8 & 2,9 & 4,5 & $3,0 \mathrm{~b}$ \\
\hline Py 5025 & 1,5 & 3,3 & 1,6 & 1,3 & 2,5 & 2,6 & 2,6 & 3,9 & 1,7 & 3,5 & 2,8 & 4,8 & $2,7 \mathrm{~b}$ \\
\hline Рy 5029 & 2,4 & 3,8 & 4,7 & 1,0 & 1,0 & 2,5 & 2,7 & 4,6 & 2,1 & 4,0 & 3,2 & 3,0 & $2,8 \mathrm{~b}$ \\
\hline Py 5038 & 0,1 & 0,2 & 0,4 & 0,0 & 0,0 & 1,9 & 2,7 & 1,7 & 2,8 & 3,2 & 0,4 & 0,1 & $1,1 \mathrm{de}$ \\
\hline Рy 5039 & 4,1 & 3,7 & 4,6 & 0,4 & 0,2 & 5,0 & 4,7 & 5,0 & 5,0 & 5,0 & 5,0 & 5,0 & $3,9 \mathrm{a}$ \\
\hline Рy 6001 & 4,5 & 3,9 & 3,8 & 3,1 & 4,7 & 4,8 & 2,8 & 4,8 & 4,3 & 4,0 & 4,8 & 4,4 & $4,1 \mathrm{a}$ \\
\hline Рy 6008 & 2,0 & 3,1 & 2,7 & 3,6 & 2,4 & 1,7 & 3,6 & 5,0 & 0,8 & 2,7 & 1,7 & 1,9 & $2,6 \mathrm{~b}$ \\
\hline Рy 6010 & 0,1 & 1,2 & 3,0 & 0,5 & 0,0 & 0,3 & 0,0 & 1,6 & 0,2 & 0,5 & 2,3 & 0,2 & $0,8 \mathrm{e}$ \\
\hline Рy 6012 & 0,0 & 0,8 & 1,5 & 0,1 & 0,0 & 3,3 & 0,1 & 1,9 & 0,4 & 0,2 & 0,3 & 1,2 & $0,8 \mathrm{e}$ \\
\hline Рy 6018 & 0,0 & 1,5 & 3,0 & 0,0 & 2,5 & 3,0 & 0,2 & 1,7 & 0,6 & 0,2 & 1,6 & 0,0 & $1,2 \mathrm{de}$ \\
\hline Рy 6025 & 2,8 & 0,6 & 1,2 & 0,0 & 0,1 & 1,1 & 1,5 & 3,4 & 4,4 & 2,2 & 0,2 & 0,1 & $1,4 \mathrm{~cd}$ \\
\hline Рy 6030 & 4,6 & 2,2 & 4,2 & 4,0 & 4,8 & 5,0 & 3,2 & 5,0 & 4,1 & 4,6 & 5,0 & 4,8 & $4,3 \mathrm{a}$ \\
\hline Média & $2,0 \mathrm{D}^{2}$ & $1,9 \mathrm{D}$ & $2,7 \mathrm{~B}$ & $1,8 \mathrm{D}$ & $1,9 \mathrm{D}$ & $2,5 \mathrm{BC}$ & $2,2 \mathrm{CD}$ & $3,2 \mathrm{~A}$ & $2,6 \mathrm{BC}$ & $2,7 \mathrm{~B}$ & $2,5 \mathrm{BC}$ & $2,6 \mathrm{BC}$ & \\
\hline
\end{tabular}

*Os números 2, 8, 9, 23, 26, 54, 61, 83, 86, 92, 93, 95.correspondem aos genótipos NE 20156-B,PF 844001, PF 844002, PF 964009, PF 804002, BR 18, CNT 8, BRS 120, BRS 194, BRS BURITI, BRS CAMBOATÁ, BRS LOURO, respectivamente.

${ }^{1}$ Valores correspondentes a s notas da escala utilizadas para classificar a severidade da doença nos diferentes genótipos de trigo

${ }^{2}$ Valores seguidos da mesma letra maiúscula na linha e minúscula na coluna não diferiram estatisticamente pelo testes de Tukey a $5 \%$ 
Os genótipos de trigo sintético avaliados no estádio de planta adulta destacaram-se tanto na reação em folha quanto em espiga por apresentar menor área afetada pela doença. Porém, em planta jovem a maioria desses genótipos se comportou como suscetível, com exceção de NE 20158$\mathrm{X}$ que apresentou apenas $10,48 \%$ de área foliar afetada. $\mathrm{Na}$ literatura não são encontrados registros sobre a resistência de genótipos de trigo sintético à brusone no Brasil, o que sugere pesquisas com maior aprofundamento, uma vez que esse germoplasma é derivado da espécie afim Aegilops tauschii (Triticum tauschii) ancestral do trigo de panificação e considerada fonte promissora de resistência à brusone e a outras doenças do trigo (Prestes et al., 1994; Almeida, 2006). Urashima \& Kato (1994) relataram resistência em acessos de Aegilops em plantas jovens, fato não foi confirmado para os genótipos de trigo sintético avaliados no presente trabalho, onde a maioria mostrou-se suscetível. Os dados obtidos no presente trabalho concordam com aqueles relatados por Urashima \& Kato (1998), com respostas diferentes do trigo em relação a alguns isolados de $P$. grisea variáveis com o estádio de desenvolvimento das plantas. Porém, Arruda et al. (2005) verificaram correlação positiva entre suscetibilidade nas folhas no estádio vegetativo e na espiga. Nesse sentido, a discordância em relação à resposta dos genótipos conforme o estádio de desenvolvimento da planta tem sido relatado por inúmeros autores, em especial para brusone do arroz (Villareal et al., 1980; Prabhu \& Bendendo, 1991; Prabhu \& Filippi, 2006). De acordo com Ou (1985), linhagens de arroz, com resistência em planta jovem, seriam resistentes em planta adulta, entretanto, a perda da correspondência em alguns cultivares pode ser atribuída a outros fatores como ambiente e "escape", situação por vezes representada pela ausência de condições favoráveis para o desenvolvimento da brusone durante o estádio de maior suscetibilidade do hospedeiro (Bonman, 1992).

Dentro da base genética apresentada pelo trigo hexaplóide cultivado (Bered et al., 2000) tem sido rara a possibilidade de existência de genes de resistência à brusone, comprovado pelos relatos de elevado número de cultivares suscetíveis à doença nas principais regiões tritícolas do Brasil (Goulart, 2004). Portanto, o número de fontes de resistência encontradas em trigo hexaplóide (Triticum aestivum L.) é reduzido e torna a base genética dessa cultura muito estreita. Por essa razão é importante que sejam identificadas novas fontes de resistência parcial à brusone para uso nos programas de melhoramento genético de trigo para essa característica e a alternativa mais viável é a busca de novas fontes de resistência dentro do germoplasma de trigo hexaplóide sintético que pode ser hibridizado diretamente com o trigo de panificação para transferência da resistência à brusone. Os genótipos de trigo sintético se constituem, portanto, em promissoras fontes de resistência a essa doença uma vez que são derivados de acessos de $T$. tauschii geneticamente distintos, que apresentam diferentes graus de resistência a doenças foliares (Prestes et al., 1994; Almeida, 2006) e capazes de herdar genes de resistência do parental diplóide (Cox et al., 1995). Além disso, a identificação de patótipos de $P$. grisea é extremamente útil para monitorar a diversidade genética do patógeno nas diferentes regiões produtoras de trigo e orientar ações dos programas de melhoramento de trigo visando resistência à brusone.

\section{AGRADECIMENTOS}

A primeira autora agradece à Coordenação de Aperfeiçoamento de Pessoal de Nível Superior - CAPES pela concessão de bolsa de estudo, à Embrapa Trigo pela estrutura física disponibilizada para a condução do trabalho, e às pesquisadoras Dra. Marta Cristina Corsi Filippi e Dra. Jurema Schons pelas sugestões de correções do texto da dissertação que originou esta publicação.

\section{REFERÊNCIAS BIBLIOGRÁFICAS}

Almeida AB (2006) Identificação e caracterização de fontes de resistência à ferrugem da folha em Triticum tauschii Coss. Schmal. Dissertação de Mestrado. Universidade de Passo Fundo. Passo Fundo RS.

Arruda MA, Bueno CRNC, Zamprogno KC, Lavorenti NA, Urashima AS (2005) Reação do trigo a Magnaporthe grisea nos diferentes estádios de desenvolvimento. Fitopatologia Brasileira 30:121-126.

Bered F, Carvalho FIF, Barbosa Neto JF (2000). Variabilidade genética em trigo. Biotecnologia Ciência e Desenvolvimento 14:22-25.

Bonman JM (1992) Durable resistance to rice blast diseaseenvironmental influences. Euphytica 63:115-123.

Cox TS, Sears RG, Bequette RK, Martin TJ (1995) Germplasm enhancement in winter wheat $\mathrm{x}$ Triticum tauschii backcross populations. Crop Science 35:913-919.

Goulart ACP. Perdas em trigo causadas pela brusone. Disponível em:<http://www.Ufv.br/dfp/workshop/Resumos/perdas\%20trigo $\% 20$ brusonepdf $>$ Acesso em 09 set.2004.

Goulart ACP, Paiva FA, Andrade PJM (1995) Relação entre a incidência da brusone em espigas de trigo e a presença de Pyricularia grisea nas sementes colhidas. Fitopatologia Brasileira 20:184-189.

Haun JR (1973) Visual quantification of wheat development. Agronomy Journal 65:116-119.

Igarashi S, Utiamada CM, Igarashi LC, Kazuma AH, Lopes RS (1986) Pyricularia sp. em trigo. I. Ocorrência de Pyricularia sp. no estado do Paraná. Resumos, 14. Reunião Nacional de Pesquisa de Trigo. Londrina PR. Instituto Agronômico do Paraná IAPAR.

International Rice Research Institute. (1996) Standard evaluation system for rice. $4^{\text {nd }} \mathrm{Ed}$. Manila.

Ou HS, Ayad MR (1968) Pathogenic races of Pyricularia oryzae originating from single lesions and monoconidial cultures. Phytopathology 58:179-182. 
Ou SH (1985). Rice diseases. 2nd Ed. Kew. Commonwealth Mycology Institute.

Parlevliet JE (1979) Components of resistance that reduce the rate of epidemic development. Annual Review of Phytopathology 17:203-222.

Parlevliet JE (1985) Resistance of the non race-specific type. In: Bushnell WR, Roelfs AP (Eds.) The Cereal Rusts vol II: Diseases, distribution, epidemiology and control. New York NY. Academic Press. pp.501-525.

Perrier X, Jacquemoud-Collet JP Darwin software. Disponível em: <http://darwin.cirad.fr/darwin >. 2006.

Prabhu AS, Bedendo IP (1991) Avaliação de resistência horizontal a brusone em cultivares de arroz. Fitopatologia Brasileira 16:3439.

Prabhu AS, Filippi MC (2006) Brusone em arroz: controle genético, progresso e perspectivas. Santo Antônio de Goiás GO. Embrapa Arroz e Feijão.

Prestes AM, Angra DC, Barbosa MM, Moraes-Fernandes MIB (1994) Fontes de resistência a Stagonospora nodorum em Aegilops squarrosa, espécie afim ao trigo cultivado. Fitopatologia Brasileira 19:510-513.

Quamaruzzaman M, Ou HS (1970) Monthly changes of pathogenic races of Pyricularia oryzae in a blast nursery. Phytopathology 60:1266-1269.
Statistical Analysis System (2003) SAS: Statistical Analysis System-Getting Started with the SAS Learning Edition. Cary NC. SAS Institute Inc.

Trindade MG, Prabhu AS, Só e Silva M (2006) Resistência parcial de genótipos de trigo a brusone nas folhas. Comunicado Técnico Online, no. 201. Disponível em: http://www.cnpt.embrapa.br/ biblio/co/p_co201.htm. Passo Fundo RS. Embrapa Trigo.

Urashima A, Kato H (1994) Varietal resistance and chemical control of wheat blast fungus. Summa Phytopathologica 20:107112.

Urashima A, Kato H (1998) Pathogenic relationship between isolates of Pyricularia grisea of wheat and other host at different host developmental stages. Fitopatologia Brasileira 23:30-35.

Urashima AS, Lavorenti NA, Goulart ACP, Mehta YR (2004) Resistance spectra of wheat cultivars and virulence diversity of Magnaporthe grisea isolates in Brazil. Fitopatologia Brasileira 29:511-518.

Villareal RL, Mckenzie DR, Nelson RR, Coffeman WR (1980) Apparent infection rates of Pyricularia oryzae on different rice cultivars. Phytopathology 70:1224-1226.

Zadoks JC, Chang TT, Konzak CF (1974) A decimal code for the growth stages of cereals. Weed Research 14:415-421.

TPP 9015 - Recebido 30 Janeiro 2009 - Aceito 1 Dezembro 2009 Editor de Seção: Carlos R. Casela 